\title{
Imagens de Pagu: trajetória midiática e construção de um mito*
}

\author{
Everardo Rocha** \\ Lígia Lana***
}

\section{Resumo}

Este artigo investiga a trajetória midiática de Patrícia Galvão (1910-1962). Sua aparição, quando se tornou conhecida no bojo do modernismo brasileiro, $e$ as duas subsequentes fases de sua trajetória - presa política e torturada; jornalista e crítica cultural - são examinadas. Analisamos jornais $e$ revistas, biografias e estudos acadêmicos, apresentando significados das imagens de Pagu. Ela desempenhou inúmeras atividades artísticas, políticas e culturais, permitindo uma inconstância que fez de si permanentes fragmentos capazes de múltiplas combinações. Sugerimos algumas hipóteses para o apagamento e o ressurgimento de Pagu no imaginário brasileiro.

Palavras-chave: Pagu, Mídia, Cultura Brasileira, Fama.

* Recebido em 14 de junho de 2017, aceito em 29 de maio de 2018.

** Professor-Associado do PPGCOM PUC-Rio, Rio de Janeiro, Brasil. everardo@puc-rio.br / https://orcid.org/0000-0001-5821-1917

*** Bolsista de Pós-Doutorado (PAPDRJ/Capes-Faperj) do PPGCOM PUC-Rio, Rio de Janeiro, Brasil. ligialana@gmail.com / https:/orcid.org/0000-0002-23971008 
Images of Pagu: Media Trajectory and The Making of a Myth

\begin{abstract}
This article investigates the media trajectory of Patrícia Galvão (1910-1962), who became known as Pagu. It examines the time she became known at the heart of the Brazilian modernist movement and two later phases - as a political prisoner who was tortured and as a journalist and cultural critic. We analyze newspapers and magazines, biographies and academic studies and discuss meanings of Pagu's image. She performed countless artistic, political and cultural activities, giving space to an inconsistency that composed permanent fragments of herself capable of multiple combinations. We suggest some hypotheses for the erasure and resurgence of Pagu in the Brazilian imaginary.
\end{abstract}

Keywords: $\quad$ Pagu, Media, Brazilian Culture, Fame. 


\section{Pagu, rainha do Anhangabaú}

O objetivo deste trabalho é examinar a trajetória midiática de Patrícia Galvão (1910-1962). Reconhecida e celebrada por suas múltiplas e dispersas contribuições - artísticas, políticas e literárias -, mas também obnubilada por uma complexa rede de estereótipos femininos - musa de beleza, mito do feminismo $e$ femme fatale -, desde 1929, quando iniciou sua carreira pública, Pagu foi representada pela mídia a partir de pautas, tendências, posicionamentos e visões de mundo as mais diversas. Escritora, tradutora, desenhista, poeta, ativista política e jornalista, ao longo de sua vida pública, Pagu tornou-se um mito feminino brasileiro, uma Leila Diniz (Goldenberg, 1995) avant la lettre, ícone na vida social de nosso país.

As diferentes matizes que contribuíram para a criação das múltiplas imagens, representações $e$, no limite, do mito Pagu fazem parte do imenso repertório de leituras que seu nome propicia ainda hoje. Ela foi tema e inspiração de atividades tão díspares quanto o filme Eternamente Pagu (BRA, 1987), de Norma Bengell, a canção popular Pagu, composta por Rita Lee, em 2000, ou a personagem de minissérie Um Só Coração, exibida pela Globo, em 2004. Também é a designação de uma ONG de proteção aos direitos das mulheres (Instituto Patrícia Galvão) e de um núcleo de estudos da Unicamp (Núcleo de Estudos de Gênero Pagu). O nome Pagu, nesse sentido, parece transitar, flutuando com desenvoltura pelos universos pop, acadêmico e político, mobilizando particularmente reflexões em torno das questões de gênero.

Em nosso trabalho anterior, concluímos que a presença da atriz francesa Sarah Bernhardt no Rio de Janeiro contribuiu para a discussão dos papéis de gênero no cenário da sociabilidade urbana brasileira, estabelecendo um possível estatuto da mulher moderna e emancipada em um país colonizado, que muito recentemente havia se liberado de sua metrópole (Rocha; Lana, 2017). Nas visitas ao Brasil, observamos que Sarah Bernhardt formulou e manejou representações e utilizou, incisivamente, 
práticas de comunicação para se estabelecer no imaginário artístico e cultural brasileiro.

Neste novo estudo, procuramos indagar, de maneira semelhante, as imagens de Pagu na mídia brasileira, analisando a criação de uma figura emblemática da arte, da política e da sociabilidade na primeira metade do século XX. A permanência de sua fama hoje sugere que, além de sua atuação artística e política, Pagu foi uma figura midiática, que soube, como Sarah Bernhardt o fez em suas viagens (Rocha; Lana, 2017), construir suas próprias imagens e se apresentar, em diferentes situações e com diferentes objetivos, como uma mulher relevante para o imaginário brasileiro. Pagu também foi narrada e recriada pela mídia durante sua trajetória pública e após sua morte. Como discute Heloísa Pontes (2006), Patrícia Galvão tornou-se um ícone para demandas e bandeiras diversas.

Sua fama, amplificada pelos meios de comunicação (...) chegou a lugares inesperados. Pagu se multiplicou (...) Em virtude da fama crescente, era previsível que uma parte da história - $e$ da personalidade que lhe conferiu tônus - se perdesse para dar lugar a enredos edulcorantes, afeitos, enquanto forma narrativa, às construções míticas que teimam em proliferar nos tempos modernos (Pontes, 2006:433).

Nosso objetivo é examinar a biografia e a construção das representações de Pagu a partir de textos, imagens e documentos publicados na mídia brasileira. Sem reafirmar ou simplesmente descrever as construções míticas edulcorantes dos meios de comunicação de massa, investigamos a lógica de criação do mito Pagu em torno de três elementos centrais. O primeiro trata das operações da mídia para enfatizar e encobrir informações, contextos e visóes de Pagu; o segundo, das questóes de gênero repercutidas em suas imagens; $e$, o terceiro, do próprio universo das celebridades femininas.

De acordo com o material documental e bibliográfico analisado, organizamos o artigo em três seções. Em um primeiro 
momento, examinamos os modos como Pagu tornou-se uma figura feminina do movimento modernista brasileiro, discutindo como sua beleza e sensualidade eram algo fortemente enfatizado em sua atuação como artista e intelectual. Em seguida, uma segunda face de suas aparições na mídia: criminosa, presa política, perseguida e torturada e, depois, jornalista e crítica cultural. Por fim, procuramos articular alguns dos significados centrais de suas imagens que construíram "Pagu" no imaginário brasileiro.

\section{2. "Bela e assanhada": Pagu e os modernistas}

Patrícia Rehder Galvão nasceu em São João da Boa Vista, em São Paulo, em 9 de junho de 1910, mas, logo depois, aos dois anos, passou a viver com a família na capital paulista. Oriunda das classes médias - seu pai era advogado e jornalista, sua mãe, donade-casa -, Patrícia completou seus estudos na tradicional Escola Caetano de Campos, inaugurada em 2 de agosto de 1894 e primeira sede da Escola Normal paulista, que teve alunos ilustres como Sérgio Buarque de Holanda, Francisco Matarazzo, Mário e Oswald de Andrade. Além da escola, aos quinze anos, Pagu também frequentou o Conservatório Dramático e Musical de São Paulo, onde foi aluna de Mário de Andrade e Fernando Mendes de Almeida. Nesse mesmo período, ela contribuiu com o Brás Jornal, uma de suas primeiras atividades artísticas, assinando com o pseudônimo Patsy. O início da vida pública de Patrícia Galvão ocorreu poucos anos mais tarde (Campos, 2013). O período marcou a aproximação entre Pagu e os artistas e intelectuais do movimento modernista brasileiro.

O primeiro fato de destaque em sua trajetória públicomidiática acontece em 1927, quando ela conheceu o cineasta Olympio Guilherme, que a persuadiu a se inscrever no Concurso Fotogênico de Beleza Feminina e Varonil, organizado pelos estúdios Fox. A disputa - narrada na biografia Pagu: vida-obra, de Augusto de Campos, e no filme Eternamente Pagu (BRA, 1987) concederia como prêmio uma viagem a Hollywood $e$ a atuação no cinema norte-americano. Pagu não venceu, mas sua 
participação no concurso sugere que ela não só tinha consciência dos poderes inerentes à sua beleza, como prezava o conteúdo aprendido no Conservatório Dramático e Musical e considerava viável o projeto de uma carreira na nascente arte cinematográfica. Ao mesmo tempo, ao participar de um concurso cujo prêmio era atuar em filmes dos estúdios Fox (Campos, 2013), Pagu parecia disposta a ingressar na fábrica de estrelas de Hollywood, onde não importava muito a qualidade da atuação dos atores, mas, sim, a beleza, necessariamente cultivada e manipulada pelas técnicas do cinema, como explica Edgar Morin (1989). Ao disputar o prêmio, Pagu afirmava sua beleza, que seria tão exaltada nos anos que se seguiram ao concurso de fotogenia.

O primeiro registro que encontramos do nome de Patrícia Galvão em periódicos da Biblioteca Nacional data de 20 de janeiro de 1923, na coluna Registro de Arte do jornal Correio Paulistano. A "senhorita Patrícia Galvão" havia deixado sua assinatura no livro de visitas da exposição do pintor João Dutra, em exibição na Casa Sotero, no Centro de São Paulo. Patrícia estava acompanhada de sua irmã mais velha, Maria Conceição, cujo nome também apareceu no jornal, "senhorita Maria C. Galvão". Em 10 de outubro de 1928, o Correio Paulistano e o Diário Paulistano anunciavam a homenagem das "professorandas" das escolas normais de São Paulo ao "dia do mestre". Cerca de trinta alunas fariam, ao meio-dia, uma preleção sobre temas diversos. Na relação de nomes, Patrícia Galvão foi a primeira listada, com o tema Água Rasa, bairro da região da Mooca. Dias antes, em 29 de setembro, a "normalista" Patrícia Galvão aparecera em lista semelhante do Diário Paulistano: era uma das alunas-entertainers da posse da nova diretoria do Centro 2 de Agosto. Como se nota, nas primeiras ocorrências, o nome de Patrícia Galvão associa-se ao universo da arte e da cultura visitando uma exposição e engajando-se nas atividades artísticas $e$ culturais da Escola Caetano de Campos.

Também na década de 1920, portanto ainda como uma teenager, há um registro de Patrícia Galvão nos periódicos pesquisados que, embora seja apenas uma nota, é muito 
significativo para a compreensão do início da vida pública de Pagu. Em 7 de agosto de 1929, os jornais cariocas O Paiz, Correio da Manhã e Diário Carioca e também o Correio Paulistano informavam que a pintora Tarsila do Amaral havia recebido, no Palace Hotel, no Rio de Janeiro, uma homenagem "(...) dos artistas, intelectuais e representantes da alta sociedade" por sua primeira exposição no Brasil (Homenagem..., 1929:1). Na ocasião, Tarsila foi presenteada com um exemplar "raríssimo" da obra Viagem ao Brasil, de Spix e Martius. Durante o evento, Elsie Houston Péret, Adauto Filho e Antônio Bento de Araújo Lima cantaram canções brasileiras; Eugênia e Álvaro Moreyra, Murillo Mendes, Patrícia Galvão (Pagu) e Oswald Andrade "disseram versos".

Na breve nota, Pagu não estava apenas presente na comitiva que homenageava Tarsila do Amaral: ela foi uma das entertainers do acontecimento, declamando poesias ao lado de nomes importantes do movimento modernista, como Murilo Mendes e Oswald de Andrade. Registradas pelos jornais, a sociabilidade e a amizade de Pagu com os artistas modernistas em sua maioria, bem mais velhos, experientes $e$ muito mais reconhecidos que ela - pareciam consolidadas. A jovem tinha, na época, dezenove anos.

A construção do mito Pagu teve início com a afirmação e o reconhecimento de sua beleza e, paralelamente, com a criação e a fama de seu nome. O processo de conferir nome aos indivíduos tem como objetivo produzir pessoas singulares; como discute Pierre Bourdieu (1986), ao nomear uma vida humana em seu nascimento, atribuímos constância à inconstância da vida biológica e social. Assim, o ato de nominação social é uma ilusão: pretende-se trazer estabilidade à existência, que se caracteriza pela imprecisão, instabilidade e não linearidade. Enquanto ato de atribuição, o nome próprio nunca corresponde à existência, ele é uma abstração. O apelido, seja ele Pagu ou Pelé, é algo além, como uma segunda nominação, que é atribuída publicamente por um grupo a um dado ator social e cujo alcance pode ser bem 
maior do que a nominação fundadora da singularidade e da constância.

Fundamentais para as celebridades, nomes, apelidos $e$ pseudônimos reconhecidos e lembrados ao longo dos anos pelo público representam a estabilidade da fama, a notoriedade visível de um nome singular diante da maioria de tantos outros anônimos. Pagu foi um apelido inventado pelo poeta Raul Bopp e divulgado pela primeira vez na revista Para Todos..., em 1928, no poema Coco de Pagu, ilustrado por Di Cavalcanti.

Pagu tem os olhos moles / uns olhos de fazer doer. / Batecoco quando passa. / Coração pega a bater. / Eh Pagu eh! / Dói porque é bom de fazer doer. / Passa e me puxa com os olhos / provocantissimamente. / Mexe-mexe bamboleia / pra mexer com toda a gente. / Eh Pagu eh! / Dói porque é bom de fazer doer. / Toda a gente fica olhando / o seu corpinho de vai-e-vem / umbilical e molengo / de não-sei-oque-é-que-tem. / Eh Pagu eh! / Dói porque é bom de fazer doer. / Quero porque te quero / Nas formas do bem-querer. / Querzinho de ficar junto / que é bom de fazer doer./ Eh Pagu eh! / Dói porque é bom de fazer doer (Bopp, 1928:24).

O texto destaca a expressividade do corpo de Patrícia Galvão: não apenas o poeta é "provocado" pelos "olhos moles" de Pagu que "passa" e o "puxa com os olhos"; seu "corpinho vai$e$-vem" que "mexe-mexe, bamboleia" e mexe com "toda a gente" $e$ "é bom de fazer doer". O poema faz uma referência nítida à sexualidade. Pagu é, sobretudo, desejável no sexo, no prazer do "mexe-mexe", no "vai-e-vem" dos corpos. Flanando tal e qual Garota de Ipanema, Pagu seria uma figura estonteante, cuja simples presença parecia bastar para sua importância. Sua fama, de acordo com o apelido bem-sucedido do poema, não demandaria nada além de seu corpo e de sua pessoa carismática, admirada no ambiente de sociabilidade dos modernistas. 
"Pagu" era uma brincadeira com as silabas de seu nome:

Ela lhe mostrara alguns poemas e ele sugeriu que adotasse esse nome de guerra literário. (...) Sidéria [irmã de Pagu] recorda que Patrícia chamava a Bopp de seu "padrinho" e que ele, a princípio, pensara que o seu nome fosse Patrícia Goulart, donde "Pagu" teria derivado (Campos, 2013:665).

O minimalismo do apelido, duas sílabas de fácil pronúncia, ia ao encontro dos propósitos artísticos dos modernistas. Decomposição anárquica do nome de Patrícia, o nome Pagu era simples e antropofágico. Ao mesmo tempo, o nome estabilizou e assinalou a singularidade de sua desenvolta circulação no ambiente modernista. Pagu era vista uma espécie de "mascote" e "boneca" do modernismo no Brasil, que passava da primeira para segunda fase.

Em Aos trancos e barrancos, Darcy Ribeiro denominou 1929 como "Ano da Pagu". O texto é ilustrado pelo retrato feito por Di Cavalcanti (no poema Coco de Pagu) e também por uma das páginas do Álbum de Pagu. O antropólogo explica o título de 1929: "Patrícia Galvão - Pagu -, moderna, bela e assanhada, a brasileira mais inteligente de sua geração, escreve e desenha, menina ainda, seu primeiro livro: Pagu. Um caderninho sacaníssimo" (Ribeiro, 1985:81).

Darcy Ribeiro sintetizou os principais sentidos da construção inicial das imagens de Pagu - "bela", "assanhada" e "a mais inteligente de sua geração". No entanto, o Álbum de Pagu, ou Pagu: nascimento, vida, paixão e morte, não foi publicado em 1929; o livro único e manuscrito, com 28 páginas de poemas e ilustrações, foi um presente dado à Tarsila do Amaral, para quem Pagu dedicou a obra. Somente em 1975, a obra foi descoberta por José Luís Garibaldi “(...) entre alguns documentos de Tarsila, que ficaram com seu sobrinho Oswaldo Estanislau do Amaral" (Campos, 2013:91) e publicada na revista Código $n^{\circ} 2$, por

1 Adjetivos utilizados em diversas passagens da obra organizada por Augusto de Campos (2013) e na resenha de Heloísa Pontes (2006). 
iniciativa de Augusto de Campos. Nesse sentido, a primeira publicação de Patrícia Galvão - "menina" que "escreve e desenha" - acontece somente alguns anos mais tarde, em 1933, com o romance proletário Parque Industrial, que nada tem do Álbum de Pagu.

No começo de sua vida pública, Pagu era menos conhecida por escrever e mais por ser declamadora e ilustradora - alguns desenhos de sua autoria foram publicados na Revista de Antropofagia e na revista Para Todos... entre 1928 e 1929. Nas páginas da Revista de Antropofagia, "(...) seus companheiros, artistas plásticos, (...) seriam nada menos que Di Cavalcanti, Cícero Dias e Tarsila. (...) Depois de Tarsila, é Pagu quem mais colabora" (Campos, 2013:89-90). Os traços dos desenhos de Pagu imitam o estilo de Tarsila. No Álbum de Pagu, "(...) a marca de Oswald e de Tarsila é evidente" (Campos, 2013:91).

Durante a homenagem à pintora Tarsila do Amaral no Palace Hotel, no Rio de Janeiro, em 1929, Pagu concedeu uma entrevista à revista Para Todos... e, ao ser indagada sobre as pessoas que admirava, ela responde: "Tarsila, Padre Cícero, Lampião e Oswald. Com Tarsila fico romântica. Dou por ela a última gota do meu sangue. Como artista só admiro a superioridade dela" (apud Campos, 2013:90). Evidentemente, aquela era uma excursão em homenagem à primeira exposição da pintora no Brasil, e as respostas de Pagu possivelmente refletiam a atmosfera lisonjeira do evento. No entanto, ao declarar que daria "a última gota de sangue" por Tarsila, Patrícia enfatiza sua proximidade e sua exagerada devoção à artista, em uma referência aos afetos femininos.

Como entertainer-declamadora, além da homenagem no Palace Hotel, Pagu também foi notícia pela participação no espetáculo promovido por Didi-Caillet, em 1929. Em 7 de junho de 1929, o Diário Nacional trouxe, em sua capa a matéria: "DidiCaillet, a encantadora rainha da beleza paranaense, (...) promoveu, no Theatro Municipal, um elegante festival em benefício da Cruz Azul e do Hospital S. Paulo, de Campos do Jordão" ("Senhorita...", 1929:1). No evento, Didi-Caillet, 
celebridade por ter vencido o concurso Miss Paraná, declamou "(...) com sua voz maravilhosa (...) lindos versos de poetas nacionais". Segundo o Diário, admirada pela "aristocracia" e pela "massa popular", Didi-Caillet foi capaz de reunir, no festival, "(...) figuras de acentuado relevo" das artes e letras, como Menotti del Pichia, Yvonne Daumerie, Cornélio Pires e Patrícia Galvão. Esse evento é muito lembrado nas biografias de Pagu, uma vez que o casal Tarsila e Oswald foram responsáveis pela direção das cenas que ela representou - Tarsila cuidou do figurino, e Oswald, da seleção de poesias. Nos dias posteriores, o Diário Popular e também outros jornais resenharam a apresentação.

O número "esquisito" do programa foi o da senhorita Patrícia Galvão (Pagu). Pagu recitou versos e poemas antropofágicos e o auditório ficou indeciso por instantes. Depois, aplaudiu-a com calor. E não havia outro remédio. A jovem recitalista estava realmente alheia ao julgamento da plateia e foi dizendo seus versos e seus poemas com a convicção de quem sente todo o entusiasmo de uma arte nova (apud Campos, 2013:717).

O convite para participar do evento surgiu porque Didi conhecera Pagu em uma festa na casa de Tarsila e Oswald. A amizade e a convivência de Pagu com o casal foram intensas: recitais, homenagens, trabalho na Revista de Antropofagia, viagens e reuniões. Além de determinante para o começo de sua trajetória artística, a ligação com Tarsila e Oswald marcou o primeiro escândalo vivido por Pagu: ela e Oswald se apaixonaram, e o casamento dele com Tarsila chegou ao fim. "Se o lar de Tarsila vacila, é pelo angu da Pagu" (apud Campos, 2013:721-722), escreveu Oswald em um guardanapo durante um jantar no Automóvel Clube.

No final de 1929, Pagu se casou com o pintor Waldemar Belisário, velho conhecido da família de Tarsila do Amaral e que vivia nos fundos de sua casa. Mas o casamento era uma farsa: Pagu estava grávida de Oswald - seu primeiro filho, Rudá de 
Andrade, nasceria em setembro de 1930 - e Belisário devia favores a Oswald, aceitando participar do arranjo que salvaria as aparências da família. No caminho para a lua-de-mel, Oswald aguardava Pagu, como haviam combinado em segredo, $e$ viajaram juntos. Poucos dias mais tarde, anunciaram a verdadeira união. Sidéria, imediatamente proibida de se encontrar com a irmã, revelou em depoimento a Augusto de Campos que Tarsila do Amaral, ironicamente, enviara de presente de casamento a Pagu e Belisário um quadro com a imagem de um touro (Campos, 2013).

O episódio envolvendo as conhecidas personalidades composto de uma miríade de atos transgressores: a infidelidade de Oswald, a traição de Pagu à amiga Tarsila, o casamento de fachada com Belisário e o filho fora do casamento - provocou fofocas e mexericos. "Quando Oswald rompeu com Tarsila, ligando-se a Patrícia Galvão, foi repudiado pela sociedade (...)", narrou Flávio de Carvalho no O Estado de S. Paulo, em 24 de outubro de 1964 (apud Campos, 2013:722).

Para que ocorra a estabilização do nome de uma celebridade, é necessária a exposição de assuntos relacionados às suas vidas privadas. Nesse processo, o jornalismo de celebridade, através de tabloides, revistas de fofoca e colunas sociais, desempenha um papel fundamental, descobrindo e divulgando "furos" sobre a vida íntima das pessoas famosas (Lana, 2014). Apresentando temas de pouca ou nenhuma natureza informativa, as notícias de celebridades são envernizadas pela retórica de um tipo de jornalismo que Charles Ponce de Leon (2002) chamou de "interesse humano".

Nesse sentido, a união de Oswald e Pagu, mesmo vista de maneira negativa, atraiu mais celebridade para ela. Ao revelar $e$ debater assuntos íntimos (amor, sexo, casamento, infidelidade, gravidez...), o caso despertou atenção e interesse sobre a trajetória de Patrícia, agora casada com um dos nomes mais significativos da literatura brasileira. Quem era aquela jovem mulher, discípula de Tarsila e promissora entertainer, que havia se casado com Oswald de Andrade? Na trajetória de mitificação de Pagu pela 
mídia, o episódio, que poderia ter sido capa de qualquer revista de fofoca, assinalou o derradeiro acontecimento de uma primeira fase, entre 1927 e 1930, momento de sua aparição como personagem pública.

Patrícia Galvão surgiu como modelo de beleza feminina moderna, expressiva e corajosa. Liberada sexualmente, ela almejava uma carreira artística e realizou, no breve período, uma trajetória como desenhista e declamadora. Pagu tornou-se conhecida e amiga de artistas modernos e, com isso, ocupou as páginas de jornais de grande tiragem - que a noticiaram, sobretudo, pela presença e pela atuação em eventos relacionados à arte e à cultura, onde estavam sempre intelectuais, pessoas da sociedade e da elite brasileira.

\section{Ativismo político, cárcere e militância cultural}

Em 1932, a revista $O$ Malho promoveu uma "grande enquete", entre uma centena de intelectuais, sobre "a maior das poetisas brasileiras". Gilka Machado levou o prêmio com 48 votos, e Maria Eugênia Celso teve o segundo lugar, com quinze. Pagu obteve módicos quatro votos. A justificativa do voto de Ary Pavão, publicada inicialmente em sua coluna Panorama, no Diário Carioca, e reproduzida em $O$ Malho, sintetiza o momento inicial de surgimento de Pagu como figura pública.

Pagu apareceu um dia em São Paulo, empolgando o ambiente artístico do grande estado com seu espírito revolucionário de escritora. Seus versos traziam um perfume de seiva moça e um calor desconhecido de modernidade. Porque - além de tudo - Pagu era bonita; e uma poetisa feia é o mesmo que ouvir a mais suave das melodias, executada pelo realejo dos homens do Periquito que tira a sorte nas ruas dos subúrbios (Pavão, 1932:3).

O voto de Ary Pavão era em uma jovem, cheia de energia e ousada, participante de um concurso de beleza de Hollywood, musa de artistas, habituée do ambiente de sociabilidade dos 
expoentes do modernismo e artista promissora. Entretanto, a partir desse início dos anos 1930, as notícias sobre Pagu assumiriam outra linha editorial. Ary Pavão encerrou seu voto sinalizando para o novo perfil:

No jornalismo paulista, Pagu fez o diabo... Arranjou polêmicas, provocou escândalos, deu tiros de revólver, levou cachações, como qualquer malandro do Morro da Mangueira - e, um dia, saiu da redação entre alas de policiais e burgueses revoltados (Pavão, 1932:3).

Ary Pavão se referia às tentativas de empastelamento do jornal $O$ Homem do Povo, que Pagu e Oswald dirigiam no início de 1931. A publicação, de curtíssima existência, com apenas dezoito dias de vida e oito números, foi invadida por estudantes de Direito em abril daquele ano. Em um dos editoriais, Oswald de Andrade afirmara que a Faculdade de Direito seria o "cancro" que destruía o Estado. Indignados, os alunos passaram a realizar protestos diários em frente à sede do jornal.

O Correio da Manhã, em 15 de abril, anunciou: "Os estudantes de Direito estão decididos a perseguir o jornal ' $\mathrm{O}$ Homem do Povo', editado nesta capital” (Os Estudantes..., 1931:3). Segundo a nota, ao deixarem o edifício onde o jornal funcionava, no Largo da Sé, Oswald e Pagu foram brutalmente agredidos pelo grupo. O casal não se atemorizou. Oswald "(...) conseguiu marcar dois ou três dos agressores, feridos no rosto", e havia quem asseverasse que Pagu "(...) fez uso de revólver e atirou duas ou três vezes contra os agressores, mas não atingiu ninguém". Segundo o Correio da Manhã, os ataques contra $O$ Homem do Povo eram lamentados pelos jornalistas de São Paulo. Depois dos episódios de violência, a polícia proibiu a circulação do periódico.

Em 1931, Oswald de Andrade e Patrícia Galvão haviam se filiado ao Partido Comunista, e O Homem do Povo refletia os ideais políticos do casal naquele período: era provocativo aos imperialistas, à Igreja e às autoridades (Campos, 2013). Pagu redigia a seção $A$ Mulher do Povo, em que criticava as "feministas 
de elite"; já as classes dominantes foram objeto da crítica de Patrícia nos artigos Maltus além, $A$ baixa da alta, $O$ retiro sexual, $A$ garupa do príncipe, Liga de trompas católicas, Saibam ser maricons, Guris patri-opas e Normalinhas, como enumerou Augusto de Campos (2013). Ela também era responsável pela coluna Correspondência, em que polemizava com as leitoras, como mostra a convocação: "Às leitoras. Recebemos colaboração de qualquer pessoa mesmo de ideologia diferente. Estabelecemos polêmica no próprio jornal. Qué apanhá pula aqui. Correspondência para Pagu" (apud Campos, 2013:137-138). Ela ainda cuidava da parte gráfica do jornal - charges, ilustrações, vinhetas e títulos. Criou uma história em quadrinhos, quem sabe uma referência a Tarsila, Oswald e ela mesma, que tinha como personagens um casal e sua sobrinha revolucionária. Alguns desses materiais foram assinados com o pseudônimo "Peste" ou apenas com a letra "P" (Campos, 2013).

Poucos meses depois do incidente no jornal, Pagu surgia em notícias novamente relacionadas à polícia. Em 31 de julho de 1931, foi presa em Santos junto com Romão Guerreiro por distribuir panfletos subversivos. De acordo com o Correio da Manhã, "Pagu não quis se submeter à intimação da autoridade policial, tornando-se necessário chamar o delegado regional, capitão Heitor Blanco" (A Prisão..., 1931:3). Naquele mesmo dia, levada para a capital paulista, a "Sra. Oswald Andrade" - "jovem artista e escritora", "redatora do jornal que existiu há pouco em São Paulo" e "escritora brilhante e mordaz" -, foi colocada em liberdade.

Menos de um mês depois, novamente em Santos, o nome de Pagu era registrado na notícia sobre um "grave conflito". $O$ Jornal explicou o que acontecera: estava sendo organizado pela Federação Sindical de Santos e pelo Socorro Vermelho Internacional um comício em homenagem a Sacco e Vanzetti ${ }^{2}$, anarquistas executados nos Estados Unidos. "A polícia (...) fez

2 Para uma versão muito interessante do caso, vale assistir ao filme "Sacco e Vanzetti" (ITA/FRA, 1971) de Giuliano Montaldo. 
seguir para o local indicado vários inspetores a fim de impedir a comemoração anunciada" (Um Conflito..., 1931:1). Entre os presentes, estavam trabalhadores, “(...) a senhora Patrícia Galvão, conhecida intelectual, e outras figuras tidas como elementos comunistas". A homenagem não foi realizada; em seu lugar, "confusão", "conflito", "bengalas", "barras de metal", por fim, "tiros" e "armas de fogo", que vitimaram fatalmente o estivador Herculano de Souza. Pagu foi presa e enviada ao Cárcere 3, na praça dos Andradas. ${ }^{3}$

Entre 1936 e 1940, a mídia noticiou outras inúmeras prisões, perseguições, audiências e liberações de Pagu, sempre relacionadas às suas atividades no Partido Comunista. Naquele momento, qualquer pessoa ou movimento organizado que ousasse criticar o autoritarismo de Getúlio Vargas em seu "Estado Novo" era duramente reprimido, com amparo da Lei de Segurança Nacional, como ocorreu na Intentona Comunista de 1935.

Antes disso, em 1932, Pagu se mudou para uma vila operária no Rio de Janeiro, por orientação do Partido Comunista. Um ano depois, Patrícia publicou o primeiro livro Parque Industrial: romance proletário, edição financiada pelo marido Oswald de Andrade. A história narra o cotidiano de mulheres operárias da região do Brás, em um dos textos ficcionais mais importantes para o retrato da nascente classe operária-urbana no Brasil. Por exigência de segurança do Partido Comunista, o livro foi assinado pelo pseudônimo Mara Lobo. Em 1933, Pagu viajou pelo mundo, publicando artigos e reportagens em jornais brasileiros, como Correio da Manhã, Diário de Notícias e Diário da Noite. Entre 1934-1935, viveu em Paris, filiando-se ao Partido Comunista francês. Depois de ser presa e quase deportada para Alemanha nazista, ela voltou ao Brasil. Naquele mesmo ano, ela se separou oficialmente de Oswald de Andrade.

\footnotetext{
3 Na canção de Rita Lee, o verso "Pagu indignada no palanque" certamente faz menção ao episódio, extensamente noticiado e muito relembrado por seus biógrafos.
} 
No início de 1936, depois de muito "empenhar-se", a Delegacia de Ordem Social conseguiu prender "Patrícia Galvão, conhecida nos meios intelectuais pelo pseudônimo de "Pagu" ("Pagu"..., 1936:7). Como narra $O$ Jornal, em 24 de janeiro de 1936, a casa onde Patrícia vivia com a irmã Sidéria, também presa na ocasião, sofreu busca rigorosa, "(...) sendo apreendida grande quantidade de material de propaganda comunista, livros, fotografias, documentos de grande importância, um mimeógrafo com todos apetrechos" ("Pagu"..., 1936:7). Todas as atividades da delegacia "recrudesceram", em função da prisão das irmãs Galvão.

Ao longo do ano de 1936, diversas matérias e reportagens noticiaram o desenrolar do processo contra Patrícia e Sidéria. Em $1^{\circ}$ de fevereiro, o jornal $A$ Noite anunciou que teve acesso ao "interessantíssimo" inquérito contra as irmãs, ligadas "intimamente" a "criminosos" inspirados por Moscou que tramavam contra o regime Vargas. "A vida delinquente de Pagu e sua irmã ficou claramente comprovada" (Agentes..., 1936:1). Sobre a prisão, ocorrida durante a reação do governo à Intentona Comunista, Darcy Ribeiro escreveu, décadas depois, que
Patrícia Galvão - Pagu - mulher bela que era a maior intelectual feminina do Brasil, líder trotsquista, ex-esposa de Oswald de Andrade, presa no Rio, é violentada com buchas de mostarda e martirizada com arame incandescente na uretra (Ribeiro, 1985:99).

Pela primeira vez, os jornais passaram a caracterizar Patrícia de maneira pejorativa. Nas duas detenções anteriores, ela ainda era "artista" e "intelectual"; a partir de 1936, ela se tornou "delinquente", "perigosa" e "extremista".

Nesse sentido, o jornal ainda lembrou que

(...) aparece no relatório o nome do pai de Pagu, Pierre [sic] Galvão, que confessava a toda gente seu profundo desgosto ao vê-la contaminada de ideias terroristas, em flagrante desacordo com a educação que recebera. 
A "ousada artista" tornara-se "terrorista", decepcionante $e$ dissidente. Alguns dias depois, a "qualificação" de Pagu diante do juiz federal foi noticiada. No jornal $A$ Noite, uma fotografia de Pagu entrando na sala de audiência estampou a capa da edição.

O repórter do jornal $A$ Noite explicou, nas últimas linhas da matéria, que conseguira falar com um "guarda moreno", carcereiro da prisão de mulheres. "Esse guarda, ouvido pela reportagem d' $A$ Noite, enquanto a vigilância que era exercida em torno de Pagu, teve esta frase: 'É uma mulher perigosa!'” (Pagu..., 1936:1). Em novembro daquele ano, absolvida pela Justiça Federal de São Paulo das acusações de realizar propaganda subversiva, Pagu permanecia detida. $O$ Jornal, em 14 de novembro, noticiou que seu advogado havia entrado com pedido de habeas corpus junto ao Supremo Tribunal Militar. Segundo o jornal, o pedido era inédito: nunca nenhuma mulher havia impetrado um habeas corpus. Pagu foi, talvez, a primeira mulher a ser detida por crimes políticos no país (Campos, 2013).

Em 1937, Pagu fugiu do Hospital Cruz Azul, para onde havia sido transferida pela justiça. Pouco tempo depois, em meados de 1938, a mídia noticiou uma nova prisão de Patrícia. Em 23 de abril, O Jornal, Correio da Manhã e Diário de Notícias informavam sobre a "destruição" de uma importante célula do partido comunista. O grupo preso era chefiado por Patrícia Galvão, ressaltaram todas as publicações, que trouxeram seu retrato em destaque. Em $O$ Jornal e no Diário de Notícias, apareceram fotografias dos sete presos, mas a imagem de destaque é de Pagu; no Correio da Manhã, o único retrato divulgado era de Patrícia.

Na narrativa do episódio, bem semelhante nos três jornais, Pagu teria disparado dois tiros contra um policial. Enquanto os investigadores recolhiam objetos e materiais subversivos em seu apartamento, Pagu ficara a sós com um dos homens $e$ "aproveitou" para alvejá-lo 
(...) por duas vezes com um revólver marca H. O., calibre 38, não atingindo felizmente o alvo. Subjugada $e$ desarmada, Patrícia Galvão, revelando revoltante cinismo, disse calmamente aos policiais que acorreram em socorro ao colega: "Agora que falhei na ocasião culminante vocês podem me levar para a polícia, pois eu bem mereço ser castigada para não mais falhar" (Destruída..., 1938:6).

A "cínica" Patrícia Galvão, cujo "nome de guerra" seria Pagu, era também, segundo o Correio, uma "perigosa agitadora" e possuía uma "faina nefasta" para subverter a ordem pública. No Diário de Notícias, Pagu aparecia como "conhecida perturbadora da ordem" e "freguesa constante dos xadrezes da Polícia Central". Em todas as notícias, os periódicos enfatizavam a derrocada do "credo vermelho" na Revolução de 1935 e as novas "operações de subversão" dos ativistas, muitos, como Pagu, também com passagens pela prisão.

Pagu, que havia permanecido por quase dois anos encarcerada, entre 1935 e 1937, foi condenada novamente a mais dois anos e meio de prisão (Campos, 2013). De 1935 a 1940, portanto, ela permaneceu por mais de quatro anos em presídios comuns e políticos, no Rio de Janeiro e em São Paulo. Segundo a mídia do período do Estado Novo, Pagu era criminosa cínica, fria e determinada. Em mais de uma reportagem, policiais avisavam que era preciso ter cuidado com Pagu, que seria uma pessoa pouco confiável; ela era "moça", mas "perigosa", o protótipo da mulher ameaçadora, traiçoeira e arrogante. Aquela bela, jovem e promissora artista tornara-se uma criminosa cínica e fria. O elogio ao esplendor de sua beleza e a exaltação de seu magnetismo feminino desapareceram.

Entretanto, a recorrência de seu rosto reproduzido nos jornais sugere que os editores acreditavam que Patrícia Galvão deveria ser exaustivamente observada pelos leitores. Os retratos, as feições e o olhar de Pagu poderiam ajudar o leitor a construir uma mulher imaginária; ao longo dos anos 1930, o perigo advindo de uma "destruidora de lares" se justapôs a um poder feminino 
raro até então: a disposição para lutar por ideais políticos, que perturbavam o Estado Novo.

Em julho de 1940, Patrícia foi libertada. Pesando 44 quilos e com a saúde muito debilitada, ela iniciou sua relação com o crítico de arte Geraldo Ferraz, com quem viveu até o final de sua vida (Campos, 2013). No mesmo mês, desligou-se do Partido Comunista. Em 1950, divulgou um texto confessional e autobiográfico revelando os traumas experimentados durante o período em que se manteve filiada.

Dos vinte aos trinta anos, eu tinha obedecido às ordens do Partido. Assinara as declarações que me haviam entregue, para assinar sem ler. Isto aconteceu pela primeira vez quando recolhi no chão o corpo agonizante do estivador negro Herculano de Souza, quando enfrentei a cavalaria na praça da República, em Santos, quando fui presa como agitadora - levada para o cárcere 3, a pior cadeia do continente. Então, quando recuperei a liberdade, o Partido me condenou: fizeram-me assinar um documento no qual se eximia o Partido de toda a responsabilidade. Aquilo tudo, o conflito e o sangue derramado, fora obra de uma "provocadora", de uma "agitadora individual, sensacionalista e inexperiente". Assinei. ASSINEI DE OLHOS FECHADOS, SURDA AO DESABAMENTO QUE SE PROCESSAVA DENTRO DE MIM. Por que não? O Partido "tinha razão". De degrau em degrau desci a escada das degradações, porque o Partido precisava de quem não tivesse um escrúpulo, de quem não tivesse personalidade, de quem não discutisse. De quem apenas aceitasse. Reduziram-me ao trapo que partiu um dia para longe, para o Pacífico, para o Japão e para a China, pois o Partido se cansara de fazer de mim gato e sapato (apud Campos, 2013:411-412).

O texto era a abertura do panfleto Verdade e Liberdade, divulgado pelo Partido Socialista Brasileiro em apoio à candidatura de Pagu nas eleições para a Assembleia Legislativa de São Paulo naquele ano. Entre a primeira prisão, em 1931, e sua 
saída do partido, em 1940, portanto, foram quase dez anos, período em que foi presa e torturada, julgada e considerada culpada de inúmeros crimes: "(...) tentaram me esganar em muito boas condições. Agora, saio de um túnel. Tenho várias cicatrizes, mas ESTOU VIVA" (apud Campos, 2013:443).

A partir daquele momento, Pagu deu início à fase mais profícua de sua atividade como escritora, jornalista e tradutora. Kenneth David Jackson (2011), que desenvolve, desde 2007, um extenso projeto de reunião, edição e publicação da produção jornalística de Pagu, sumarizou o trabalho de Patrícia após a saída da prisão em $1940{ }^{4}$

Escreve 111 colunas assinadas "ARIEL" na revista $A$ noite, de 22/08/42 até 31/12/42. De 31/08/45 a 9/8/46, publica extensos comentários sobre a inteligência, política e poesia brasileiras, em 26 colunas na Vanguarda socialista, de Mário Pedrosa. Nesse período, em parceria com o crítico de arte Geraldo Ferraz, com quem se casou em 1940, começa a série "Antologia da literatura estrangeira", no Diário de $S$. Paulo (24/11/46 até 28/11/48), dedicada a autores da literatura mundial, com mais de noventa nomes, apresentados e traduzidos por Patrícia. Continua a retratar autores mundiais no jornal $A$ tribuna, de Santos, com números especiais, dedicados a Sigmund Freud, Heinrich Heine e Rainer Maria Rilke, entre outros. Vai publicar, de 1955 a 1961, sete crônicas sobre Fernando Pessoa, que contam entre os primeiros trabalhos no Brasil sobre o consagrado poeta da vanguarda portuguesa (Jackson, 2011:34).

A partir de 1946, nos jornais Diário de São Paulo e $A$ Tribuna, de Santos, Pagu ampliou o alcance da circulação de seus textos, trabalhando em publicações de grande tiragem $e$

${ }^{4}$ Financiado pelo Programa da Fulbright American Republic, o projeto será composto de quatro volumes intitulados: $A$ denunciada denuncia, $D a$ Necessidade da Literatura, Palcos \& Atores e Antologia dos Grandes Autores Mundiais. 
fidelizando seu público pela regularidade de artigos, críticas $e$ resenhas. No Diário de São Paulo, desenvolveu a "Antologia da Literatura Estrangeira", em que traduzia e apresentava aos leitores brasileiros autores relativamente desconhecidos aqui como Apollinaire, Mallarmé, Joyce, Faulkner, Katherine Ann Porter, Carson Mac Cullers, Katherine Mansfield, Erskin Caldwell e Henry Miller (Jackson, 2006). Além disso, naquele mesmo momento, Pagu publicou seu segundo romance, A Famosa Revista. Ela escreveu também para o Jornal de São Paulo e para a revista italiana Fanfulla. Uma de suas últimas produções foi a coluna "Viu, viu, viu?", publicadas entre 1961 e 1962, em que escrevia críticas de televisão.

Como sugerem Kenneth David Jackson $(2006,2011)$ e Márcia Costa $(2011,2012)$, as contribuições de Pagu ao jornalismo brasileiro são profícuas e extensas, iniciando em sua adolescência, no Jornal do Brás, e perdurando até os últimos dias de sua vida. Nesse sentido, os especialistas indicam que seus textos mais relevantes para o jornalismo foram publicados no Vanguarda Socialista e no Suplemento Literário, veiculado no Diário de São Paulo. Não mais movida por anseios relacionados a partidos políticos - apesar de ter se candidatado em 1950 - Pagu tornouse, entre 1940 e 1962, uma ativista da cultura, das letras e das artes, preocupada com a formação de leitores e com a divulgação da literatura.

$\mathrm{Na}$ construção de sua imagem pública, notamos que, assim como nos primeiros momentos de sua aparição, Patrícia ficou próxima de figuras relevantes do cenário intelectual brasileiro, como Clarice Lispector, Carlos Drummond de Andrade, Murilo Mendes, Sérgio Milliet, Flávio de Carvalho, Antunes Filho, Lygia Fagundes Telles, entre outros (Costa, 2011).

Permaneceria inconformista $e$ fiel às vanguardas, exigente, sarcástica, adepta de fórmulas fulminantes. Como se não bastasse, sempre insubmissa na defesa dos avanços modernistas e contestatária na denúncia dos retrocessos, fossem estéticos, políticos ou comportamentais (Galvão, 2010:58). 
Essa fase como jornalista fez com que Pagu deixasse de ser noticiada - por sua "beleza", por sua "arte" ou por seus "crimes" - para se tornar produtora de suas próprias histórias. Na última fase de sua vida pública, Pagu parece ter deixado de ser objeto do discurso da mídia para se tornar sujeito de fala: ela registrou sua visão sobre o mundo, as artes, a literatura, a política, o feminismo, a cidade, a televisão, entre outros. Assim, as últimas imagens de Patrícia Galvão parecem ser de uma mulher que fala, ou que ao menos é capaz de buscar com regularidade, coerência e dedicação um lugar de discurso, um espaço relevante para a compreensão das transformações dos papéis das mulheres na modernidade. (Kehl, 2016).

\section{A bricolagem e o mito Pagu}

Com sua morte, em 1962, Pagu passou a ser rememorada $e$ celebrada por críticos, intelectuais, ativistas e artistas. Nos anos 1980, Augusto de Campos (2013) foi um dos primeiros a propor o resgate da escritora no livro Pagu vida-obra, reunindo trechos de trabalhos, entrevistas, depoimentos e histórias de vida. Em seguida, nos anos 1990, a institucionalização do Núcleo de Estudos de Gênero Pagu (Unicamp) foi um momento importante para a construção das imagens de Patrícia Galvão. O núcleo, composto de nomes importantes da antropologia no Brasil, atribuiu a Pagu um lugar de relevância no pensamento social brasileiro, situando-a como figura-chave para a problematização das questões de gênero.

Ao lado dessa versão intelectual e acadêmica, Pagu também se tornou figura de sucesso, como mencionado na abertura deste artigo, no universo pop (na música, no cinema e na televisão) e no âmbito do feminismo (com o esforço para a divulgação da biografia de Pagu entre as novas ativistas e com a criação do Instituto/Agência Patrícia Galvão, em 2009). Em 2010, ao apresentar o renovado interesse por Pagu "modernista, feminista, jornalista, libertária", Walnice Nogueira Galvão incluiu também a adoção do nome e da história de Patrícia Galvão em centros 
culturais, enredos de escola de samba, documentários, espetáculos teatrais e "(...) uma exposição mais do que completa no Museu Lasar Segall, até o início de 2010" (Galvão, 2010:56).

Esse circuito capaz de permitir o trânsito, as múltiplas colagens, as infindáveis traduções entre imagens, discursos, figuras e representações são fundamentais para a possibilidade de construção de um mito - no caso, o mito Pagu. De acordo com Claude Lévi-Strauss (1987), um mito é uma narrativa, uma forma de linguagem. Assim como a linguagem necessita de fonemas, o mito precisa de alguns elementos para ser formado. Em termos de processo de construção, o mito seria uma bricolagem, uma reorganização interessada e autônoma que poderia oferecer sempre novas versões a quaisquer antigos materiais. Esses materiais utilizados na colagem seriam vestígios, pedaços e restos de velhos mitos, que, segundo o autor, foram $e$ são continuamente refeitos pelos seres humanos ao longo do tempo. Nesse sentido, o mito
(...) não possui verdade eterna e é como uma construção que não repousa no solo. O mito flutua. Seu registro é o do imaginário. Seu poder é a sensação, a emoção, a dádiva. Sua possibilidade intelectual é o prazer da interpretação. $\mathrm{E}$ interpretação é jogo e não certeza (Rocha; Lana, 1999:94).

Nesse sentido, a mídia seria uma das instâncias centrais que, incessantemente, promovem as bricolagens através das quais se expressam os mitos na cultura hoje.

A elaboração de novas significações das imagens Pagu processo adormecido nos anos subsequentes a sua morte, porém reavivado a partir dos anos 1980 - permite pensar sobre a compreensão dos lugares da mulher na mídia e na sociabilidade brasileira. Inicialmente, nos anos 1970, a figura de Patrícia esteve silenciada, adormecida (Pontes, 2006; Campos, 2013). Sensual, assanhada e livre, Pagu não condizia com a moral e os princípios daquela mulher brasileira - ainda que as ideias feministas começassem a circular, de maneira incipiente, nas camadas 
médias. Como analisou Gilberto Velho (1998), mesmo nas rodas boêmias e esclarecidas do Rio de Janeiro dos anos 1970, os nascentes ideais de busca por "desejos individuais" e "projetos de vida autênticos" não foram acompanhados da crítica aos posicionamentos tradicionais e conservadores com relação ao comportamento das mulheres. Apesar do aparente discurso "moderno" dos informantes, foi observada a resistência às transformações sociais dos papéis das mulheres (Velho, 1998), motivadas pelo feminismo e pela revolução sexual dos anos 1960.

Pagu, nascida na longínqua década de 1910, já deslocava os lugares da mulher - no sexo, no casamento, na maternidade e na atuação pública: engravidou e abortou aos 14 anos; casou-se em segredo, separou-se pouco tempo depois e deixou, durante as longas viagens ao exterior, o filho aos cuidados do pai ou da família; filiou-se a um partido político diversas vezes na ilegalidade, mudou de ideologia e revelou as contradições da agenda comunista; acreditou na arte e investiu no que pensava ser transformação social através do jornalismo e da literatura. A liberdade sexual, a maternidade tumultuada, a disposição para viagens comprometidas com suas ideias, o engajamento político $e$ cultural, nenhuma dessas imagens pareciam adequadas para inspirar as mulheres brasileiras da década de 1970.

Além disso, as contestações e a resistência cultural que ocorreram na década de 1970, como na música popular e no cinema, nem questionaram os lugares da mulher, nem tiveram autoras de destaque (Rago, 1997). A visita de Betty Friedan ao jornal O Pasquim, em 1973, por exemplo, demonstrou as dificuldades, o preconceito e o conservadorismo dos "libertários" diante de uma mulher que era relativamente respeitada $e$ conhecida nos Estados Unidos naquele mesmo momento (Soihet, 2005). Assim, o esquecimento de Pagu até os anos 1980 não é despropositado, uma vez que suas imagens não caberiam na bricolagem possível daquele momento.

Desde os anos 1980, fragmentos de arquivos e novas produções culturais e políticas vêm permitindo a retomada das imagens de Pagu. Isso só foi possível, como mostramos, porque 
Pagu construiu ativamente sua trajetória sob os olhares vigilantes de jornais, revistas e articulistas. Seu apelido, seu rosto e seu olhar marcantes $e$ sua crença apaixonada por ideais foram iminentemente midiatizadas. Pagu se permitia "estar em cena". Levantamos a partir de agora algumas outras hipóteses para isso.

Em primeiro lugar, Pagu foi capaz de empunhar uma arma e atirar contra homens; ela foi presa e considerada violenta, mas nunca assassinou ninguém. Na recente versão do feminismo como ganho de poder de mulheres pela força, essa imagem é muito adequada. Pagu não se embruteceu completamente, não matou, mas sua imagem é capaz de transmitir o espírito combativo e a perspectiva de violência necessários à transformação social proposta pelo feminismo, que passou a ser mais aceito no Brasil desde os anos 1980 (Rago, 1997).

Em segundo lugar, Pagu sobreviveu aos contínuos reveses de sua errática trajetória. Seguiu seus variados desejos políticos, sexuais e artísticos, sofreu duras consequências por suas escolhas, mas conseguiu, ao final, casar-se, constituir uma família, posicionando-se dentro de moldes mais tradicionais do feminino. Como critica Heloísa Pontes (2006), essa seria a versão "edulcorante" da biografia de Pagu, tão necessária para a criação da colagem melodramática de uma heroína em busca de final feliz. A narrativa enaltece o perfil da mulher moderna, que possui desejos e agência individual, presentes na matriz desse melodrama e que adquire pleno sentido hoje (Abu-Lughod, 2003).

Por fim, Pagu não experimentou uma trajetória contínua e estável: não exerceu com grande destaque nenhuma ocupação ou atividade. Ela não era apenas bela (pelo desejo que despertava nos homens), ilustradora ou poeta (como pupila de Tarsila do Amaral e Oswald de Andrade), ativista política (especialmente no Partido Comunista), escritora ou jornalista (na última década de sua vida). Essa pletora de atividades que desempenhou libera uma inconstância que faz de Pagu permanente promessa de fragmentos capazes de múltiplas combinações - versátil e apta para compor mitos com diferentes tipos de apelo. 


\section{Referências bibliográficas}

ABU-LUGHOD, Lila. Melodrama egípcio: uma tecnologia do sujeito moderno? cadernos pagu (21), Campinas, SP, Núcleo de Estudos de Gênero-Pagu/Unicamp, 2003, pp.75-102.

Bopp, Raul. Coco de Pagu (poema). Rio de Janeiro, Para todos..., ano X, n ${ }^{\circ} 515,27$ out. 1928, pp.24.

BOURDIEU, Pierre. L'illusion biographique. Actes de la recherche en sciences sociales, vol. 62-63, Jun. 1986, pp.69-72.

Campos, Augusto. Pagu vida-obra. São Paulo, Companhia das Letras, 2013 [1982]. [edição kindle]

CostA, Márcia. De Pagu a Patrícia: o último ato. São Paulo, Editora Dobradura Editorial, 2012.

. Jornalismo cultural: a produção de Patrícia Galvão no jornal A Tribuna (Santos). São Paulo, XXIV Congresso Brasileiro de Ciências da Comunicação, 2011.

DA MATTA, Roberto. A casa \& a rua: espaço, cidadania, mulher e a morte no Brasil. Rio de Janeiro, Rocco, 1997.

FREIRE FILHO, João; LANA, Lígia. Pacto de visibilidade: mídia, celebridades e humilhação. Contracampo, vol. 30, 2014, pp.4-23.

Galvão, Patrícia. Paixão Pagu: uma autobiografia precoce de Patrícia Galvão. São Paulo, Agir, 2005.

GALVÃo, Walnice Nogueira. Indômita. São Paulo, Teoria e Debate, ${ }^{\circ}$ 87, mar./abr. 2010, pp.56-58.

GoldenBERg, Míriam. Toda mulher é meio Leila Diniz. Rio de Janeiro, Record, 1995.

JACKSON, Kenneth David. A Denunciada Denuncia [She who was Denounced Denounces]: Pagu and Politics, 1931-1954. An Introduction to the Journalism of Patrícia Galvão. Review: Literature and Arts of the Americas, vol. 39, issue 2, 2006, p.228-235.

. Uma evolução subterrânea: o jornalismo de Patrícia Galvão. Instituto de Estudos Brasileiros da Universidade de São Paulo, Revista IEB, $\mathrm{n}^{\circ}$ 53, mar./set. 2011, pp.31-52. 
KEHL, Maria Rita. Deslocamentos do feminino: a mulher freudiana na passagem para a modernidade. São Paulo, Boitempo, 2016.

LANA, Lígia. Jornalismo de celebridade, interesse humano e representações femininas na contemporaneidade. In: FREIRE FILHO, João; CoelHo, Maria das Graças Pinto (org.). Jornalismo, cultura e sociedade: visões do Brasil contemporâneo. Porto Alegre, Sulina, 2014, pp.174-193.

LEON, Charles Ponce. Self-exposure. Human-interest journalism and the emergence of celebrity in America (1890-1940). Chapel Hill, The University of North Carolina Press, 2002.

LÉVI-STRAUSS, Claude. Mito e significado. Lisboa, Edições 70, 1987.

MORIN, Edgar. As estrelas: mito e sedução no cinema. Rio de Janeiro, José Olympio, 1989.

NEVES, Juliana. Geraldo Ferraz e Patrícia Galvão: a experiência literária do Suplemento Literário do Diário de S. Paulo, nos anos 40. São Paulo: Annablume/Fapesp, 2005.

PONTES, Heloísa. Vida e obra de uma menina nada comportada: Pagu e o Suplemento Literário do Diário de S. Paulo. cadernos pagu (26), Campinas, SP, Núcleo de Estudos de Gênero-Pagu/Unicamp, janeirojunho de 2006, pp.431-441.

RAGO, Margareth. Adeus ao Feminismo? Feminismo e (pós)modernidade no Brasil. Cadernos do arquivo Edgar Leuenroth, vol. 3, $\mathrm{n}^{\circ} 3$, Campinas, SP, 1997, pp.11-43.

RIBEIRO, Darcy. Aos trancos e barrancos: como o Brasil deu no que deu. Rio de Janeiro, Editora Guanabara, 1985.

ROCHA, Everardo; LANA, Lígia. Fama e afetação: as passagens de Sarah Bernhardt pelo Rio de Janeiro (1886-1905). Revista Famecos, vol. 24, 2017, p.26222.

SOIHET, Rachel. Zombaria como arma antifeminista: instrumento conservador entre libertários. Revista Estudos Feministas, vol.13 (3), 2005, pp.591-611.

VelHO, Gilberto. Nobres \& anjos: um estudo de tóxicos e hierarquias. Rio de Janeiro, Editora FGV, 1998. 


\section{Fontes pesquisadas}

A PRISÃo, em Santos, da Sra. Oswaldo de Andrade. São Paulo, Correio da Manhã, ed. 11234, 31 jul. 1931, p.3.

AgENTES de Moscou! Rio de Janeiro, A Noite, ed. 8657, $1^{\circ}$ fev. 1936, p.1.

DESTRUíDA importante célula do Partido Operário Leninista. Rio de Janeiro, O Jornal, ed. 5783, p.6.

ETERNAMENTE Pagu. Direção: Norma Bengell. Rio de Janeiro: Flai Cinematográfica Ltda; Sky Light Cinema; Maksoud Plaza; Embrafilme, 1987. 35 mm, cor, 100 min.

Homenagem a Tarsila do Amaral. São Paulo, Correio Paulistano, ed. 23625, 07 ago. 1929, p.1.

Os EstudAnTES de Direito de S. Paulo e o "Homem do Povo". São Paulo, Correio da Manhã, ed.11142, 15 abr. 1931, p.3.

"PAGU" e sua irmã Sidéria presas em São Paulo. Rio de Janeiro, $O$ Jornal, ed. 5091, 24 jan. 1936, p.3.

PAGU perante a justiça. Rio de Janeiro, $A$ Noite, ed. 8663, 8 fev. 1936, p.1.

Pavão, Ary. Voto em Pagu. Rio de Janeiro, Diário Carioca, ed. 1337, 16 dez. 1932, p.3.

"Senhorita Paraná". São Paulo, Diário Nacional, ed. 592, 7 jun. 1929, p.1.

Um Conflito em Santos. Rio de Janeiro, O Jornal, ed. 3926, 25 ago. 1931, p.1. 